\title{
Urinary schistosomiasis in a child from Central Africa
}

\author{
Félix Couture MD, Audrey Desjardins MD, Patrick O. Richard MD
}

Cite as: CMAJ 2021 December 6;193:E1843. doi: 10.1503/cmaj.210510

A 12-year-old boy, a refugee from rural Central Africa who had arrived in Canada 1 month prior, presented to the emergency department with a 2-month history of hematuria and dysuria. Urinalysis showed 51-100 red blood cells per high power field, and urine culture was negative. Kidney and bladder ultrasonography showed three $1 \mathrm{~cm}$ lesions protruding from the bladder wall (Figure 1A). Serum testing for Schistosoma species was equivocal, but urine testing showed nonviable eggs from Schistosoma hematobium. To exclude bladder neoplasia, we performed cystoscopy and transurethral resection of 2 erythematous, solid-appearing masses (Figure 1B). Histological analysis showed calcified cystitis overlying schistosomiasis. The patient received 2 doses of praziquantel ( $20 \mathrm{mg} / \mathrm{kg} / \mathrm{dose}$ ) in 1 day. Fourteen months after surgery, he had fully recovered.

Schistosomiasis affects about 200 million people worldwide, most commonly in sub-Saharan Africa, but also in South America, the Middle East and Southeast Asia. ${ }^{1}$ Schistosoma species are usually found in fresh water, with snails acting as intermediate hosts. ${ }^{2}$ Poor and rural communities are at risk; children are especially vulnerable to infection from playing in water contaminated with cercariae, free-swimming infectious forms of the parasite, which can penetrate human skin. ${ }^{1,2}$

Common causes of persistent hematuria in children include urinary tract infection, acute nephritis and urolithiasis. Urinary schistosomiasis should be considered in patients from regions where the disease is endemic. Identification of flatworm eggs is diagnostic and is made through examination of host excreta (urine with S. hematobium). ${ }^{1}$ The immune response associated with acute infection commonly leads to eosinophilia, but did not in our patient. ${ }^{1}$ Cystoscopy usually shows hemorrhagic and granuloma-like "sandy patch" lesions in the bladder mucosa., Praziquantel is the mainstay of treatment. ${ }^{1}$

Long-term disease is associated with bladder stones and fibrosis, obstructive hydronephrosis and chronic inflammation, which can lead to squamous cell carcinoma. ${ }^{1}$

\section{References}

1. Gryseels B, Polman K, Clerinx J, et al. Human schistosomiasis. Lancet 2006;368:1106-18.

2. Schwartz C, Fallon PG. Schistosoma "eggs-iting" the host: granuloma formation and egg excretion. Front Immunol 2018;9:2492.

3. Bichler KH, Savatovsky I; Members of the Urinary Tract Infection (UTI) Working Group of the Guidelines Office of the European Association of Urology (EAU), et al. EAU guidelines for the management of urogenital schistosomiasis. Eur Urol 2006;49:998-1003.

4. Tan WP, Hwang T, Park J-W, et al. Schistosoma haematobium: a delayed cause of hematuria. Urology 2017;107:e7-8.

Competing interests: None declared.

This article has been peer reviewed.

The authors have obtained patient consent.

Affiliation: Division of Urology, Department of Surgery, Centre Hospitalier Universitaire de Sherbrooke, Sherbrooke, Que.

Content licence: This is an Open Access article distributed in accordance with the terms of the Creative Commons Attribution (CC BY-NC-ND 4.0) licence, which permits use, distribution and reproduction in any medium, provided that the original publication is properly cited, the use is noncommercial (i.e., research or educational use), and no modifications or adaptations are made. See: https://creativecommons.org/licenses/by-nc-nd/4.0/

Correspondence to: Patrick Richard, patrick.richard@usherbrooke.ca 